\begin{tabular}{|c|c|c|}
\hline 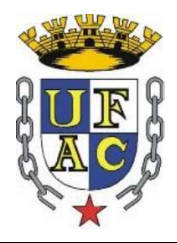 & $\begin{array}{c}\text { UÁQUIRI } \\
\text { Revista do Programa de Pós-Graduação em Geografia } \\
\text { UÁQUIRI - PPGGEO, v. 2, n. 1, p. } 80 \text { - 95, ano } 2020 \\
\text { Home page: } \underline{\text { https://periodicos.ufac.br/index.php/Uaquiri }}\end{array}$ & PPG \\
\hline & & ISSN 2675-4088 \\
\hline
\end{tabular}

\title{
TERRA CAÍDA: A LITERATURA REGIONAL COMO RESGATE DO SENTIMENTO DE "LUGAR”
}

\author{
Fernanda da Rocha Soares ${ }^{1 *}$, Cleilton Sampaio de Farias ${ }^{2}$ \\ ORCID: https://orcid.org/0000-0002-5115-3969; https://orcid.org/0000-0003-1783-3175
}

\begin{abstract}
${ }^{1}$ Pós-Graduação em Educação, Profissional, Científica e Tecnológica - EPCT do Instituto Federal do Acre (IFAC), Rio Branco-AC, Brasil; ${ }^{2}$ Professor do Programa de Pós-graduação em Geografia da Universidade Federal do Acre (UFAC), Rio Branco, Acre, Brasil; ${ }^{3}$ Professor do Instituto Federal do Acre, Rio Branco Brasil. *fernanda01.06@outlook.com
\end{abstract}

Recebido em: 26/03/2020. aceito em: 08/05/2020, publicado em: 22/06/2020 DOI:

\begin{abstract}
O lugar está relacionado a um espaço de construção de afetividades, moldadas por um conjunto de experiências vividas pelo sujeito em determinadas circunstâncias históricas, sociais e políticas, que de modo quase imperceptível acabam por influenciar em seu desenvolvimento enquanto pessoa, cidadão atuante do espaço em que se encontra e, portanto, capaz de modificá-lo e de ser, por ele, modificado. Assim, objetivou-se propor um minicurso sobre a geografia do seringal tendo como principais materiais obras literárias regionalistas que possam contribuir para o resgate do sentimento de pertencimento. Para tanto, adotou-se a abordagem qualitativa e descritiva e adotou-se o estudo de caso, a partir de revisão da literatura, a partir da qual buscou-se embasamento para o desenvolvimento da parte prática do projeto, discutindo o tema com base em referências teóricas publicadas em livros, revistas, periódicos e tantos outros suportes. Por fim, esta pesquisa deve possibilitar ao participante a competência de identificar-se com o lugar em questão, sua importância para a história do país e as disputas que ainda instiga no âmbito da política nacional e internacional, conceituando e reconhecendo lugares do qual faz parte, bem como valorizando a cultura oriunda do ambiente amazônico, a partir da qual se desenvolverá a consciência necessária para perceber sua importância.
\end{abstract}

RESUMO

Palavras-chave: Amazônia; Geografia; Literatura; Educação.

\section{TITLE: FALLEN LAND: REGIONAL LITERATURE AS A RESCUE OF THE FEELING OF "PLACE"}

\begin{abstract}
The place is related to a space for the construction of affection, shaped by a set of experiences lived by the subject in certain historical, social and political circumstances, which almost imperceptibly end up influencing their development as a person, an active citizen of the space in which they live. is, therefore, able to modify it and be modified by it. Thus, the objective was to propose a mini-course on the geography of the rubber plantation with the main materials of regional literary works that can contribute to the recovery of the feeling of belonging. To this end, the qualitative and descriptive approach was adopted and the case study was adopted, based on a literature review, from which the basis for the development of the practical part of the project was sought, discussing the theme based on theoretical
\end{abstract}


references published in books, magazines, periodicals and many other supports. Finally, this research should allow the participant the competence to identify with the place in question, its importance for the country's history and the disputes that it still instigates within the scope of national and international politics, conceptualizing and recognizing places of which it is part, as well as valuing the culture coming from the Amazonian environment, from which the necessary awareness will develop to realize its importance.

Keywords: Amazon; Geography; Literature; Education.

\section{TÍTULO: TIERRA CAIDA: LITERATURA REGIONAL COMO RESCATE DE LA SENSACIÓN $D E$ "LUGAR"}

\section{RESUMEN}

El lugar está relacionado con un espacio para la construcción del afecto, conformado por un conjunto de experiencias vividas por el sujeto en ciertas circunstancias históricas, sociales y políticas, que casi de manera imperceptible terminan influyendo en su desarrollo como persona, un ciudadano activo del espacio en el que vive. es, por lo tanto, capaz de modificarlo y ser modificado por él. Por lo tanto, el objetivo era proponer un mini curso sobre la geografía de la plantación de caucho con los principales materiales de las obras literarias regionales que pueden contribuir a la recuperación del sentimiento de pertenencia. Con este fin, se adoptó el enfoque cualitativo y descriptivo y se adoptó el estudio de caso, basado en una revisión de la literatura, a partir de la cual se buscó la base para el desarrollo de la parte práctica del proyecto, discutiendo el tema basado en referencias teóricas publicadas en libros, revistas, publicaciones periódicas y muchos otros soportes. Finalmente, esta investigación debería permitir al participante la competencia para identificarse con el lugar en cuestión, su importancia para la historia del país y las disputas que aún incita en el ámbito de la política nacional e internacional, conceptualizando y reconociendo los lugares de los que forma parte, además de valorar la cultura proveniente del ambiente amazónico, a partir del cual se desarrollará la conciencia necesaria para darse cuenta de su importancia.

Palabras clave: Amazonas; Geografia; Literatura; Educación.

\section{INTRODUÇÃO}

O sentimento de pertencimento social sempre foi um construto bastante discutido na literatura, sobretudo, naquela que se dedica a explorar as identidades sociais através da cultura de lugar, de modo que o fortalecimento e construção de identidades a partir da comunidade em que o sujeito se encontra inserido acontece, entre outros fatores, associada à partilha de problemas sociais inerentes à proximidade geográfica entre os indivíduos. Na Amazônia, tal sentimento tende a ser marcante em decorrência das inúmeras e peculiares dificuldades enfrentadas por seus habitantes, aspectos que não se observam facilmente em nenhum outro lugar do mundo.

A geografia do Acre representa, desde sua descoberta, um forte elemento de identidade do homem amazônico, cuja história se confunde com o desenvolvimento deste Estado. Quando, na altura do século XIX, viu-se o florescer de ideais nacionalistas brasileiros, mais voltados 
para a representação de uma cultura patriótica no Brasil, refletida, sobretudo, nas obras de caráter indigenista de José de Alencar, houve profunda reflexão sobre as singularidades regionais e culturais do povo, de modo que, no Acre, a metáfora mitológica construída acerca do ambiente persiste até os dias atuais. Tal conceito se materializou, naquele período, na árvore mais emblemática da região, a seringueira, símbolo de fertilidade e disputa históricas.

Assim, ao longo dos anos, a relação homem e floresta foi romantizada na Amazônia, dando origem a inúmeros escritos, estudos e pesquisas desencadeadas pelo fascínio que a mata provoca, seu silêncio e dimensões, elementos usados por Márcio Souza para retratá-la, n'A Selva, o filme de drama brasileiro de 1970, como uma "prisão sem muros", a céu aberto, onde a figura do seringueiro está irremediavelmente encarcerada, uma vez que, no Acre, antes de quatro décadas atrás, "mais da metade da população vivia nesse meio, na condição de seringueiro, ribeirinho e indígena" (ACRE, 2010).

Não foi por acaso, portanto, que o povo acreano cresceu envolto por este ambiente de características tão marcantes, cuja complexidade identitária se resume pela alcunha "povos da floresta", expressão exaustivamente explorada nos últimos anos, sobretudo no cenário político, e potencializada pelo discurso ainda presente e indelével de Chico Mendes, o ambientalista que mesmo atualmente, mais de 30 anos após sua morte, é a personagem mais representativa da luta pela defesa da floresta e dos povos que nela vivem e dela dependem para sua subsistência. Podese mesmo dizer que o homem amazônico se habituou à herança atávica do lugar, adotando e mantendo para si tal identidade como se esta fosse a única possível.

A identidade é um dos grandes temas das ciências sociais e antropológicas, estudada através de pesquisas que a relacionam frequentemente, e não sem fundamentadas razões, ao espaço de vivência do sujeito, suas subjetividades e a discussão acerca de pertencimento e produção de fronteiras atemporais, bem como as memórias, individuais e coletivas, que ajudam a defini-la. No entanto, não limita-se apenas a isso, mas para além das semelhanças, a identidade também se constrói a partir de diferenças e distanciamento, pois seu princípio parte do outro como referência, o que na visão de Bauman (2012), não ocorre com a população das comunidades isoladas, que nunca se perguntam quem são, não porque sejam obtusas e limitadas em sua imaginação, mas porque nunca lhes ocorreu ser outra coisa, buscar outra identidade fora do lugar em que vivem por falta de oportunidade, por viverem em regiões isoladas e por bastarlhes ser quem são.

Bauman (2012) ainda defende que na identidade do homem moderno é fragmentada e cheia de vazios, carente de solidez que lhe permita ser coerente. Logo, diante do exposto, 
objetivou-se a proposta de um minicurso sobre a geografia do seringal, tendo como principais materiais obras literárias regionalistas que possam contribuir para a reflexão acerca do sentimento de pertencimento, ao mesmo tempo em que desperta a necessidade de descoberta do lugar, partindo da premissa de que o seringal, apesar de ser objeto de tantos estudos e pesquisas, ainda é um espaço desconhecido e inexplorado, mesmo para aqueles que nele nasceram e cresceram e dele retiram seu sustento. Isso ocorre, sobretudo, porque não é possível falar em identidade como algo prontamente definido, mas em vez disso, de acordo com Hall (2012), deveríamos falar de identificação, já que não se pode resumir tal questão àquilo que já está dentro de nós, mas também a uma falta de inteireza preenchida a partir do nosso exterior e pela forma como supomos que os outros nos veem.

“A identidade, portanto, não é algo dado, mas é sempre processo (identificação em curso), que se dá por meio da comunicação com outros atores (diálogo e confronto). A territorialidade é expressão deste processo no cotidiano dos atores sociais" (SOUZA; PEDON, 2007, p. 135). É dessa forma que se relaciona o território, a territorialidade e a identidade territorial seja do ponto de vista do seringal ou da fazenda.

Haesbaert (1997, p. 46) esclarece que as identidades sociais são produzidas como representações simbólicas da realidade visando a um reconhecimento social da diferença. Em alguns casos, considerando o território como produto das relações sociais no decorrer de um tempo histórico expresso na materialidade e em símbolos, "a simbolização significa então concebê-lo num processo de apropriação social "[...] que tem a sua própria eficácia, ou seja, um 'poder simbólico' que, em parte, acaba forjando as identidades territoriais" (HAESBAERT, 1997, p. 49 - 50).

O poder simbólico, invisível por essência, permite obter os mesmos benefícios daquilo que é obtido com o uso da força ou poder coercitivo, por isso se apresenta irreconhecível, sem a distinção daquele que o exerce, mas, mesmo assim, forma uma rede de aspectos - símbolos e representações - que espalhados pelo território permitem constituir a identidade territorial (HAESBAERT, 1997, p. 50).

Nesse sentido, a identidade territorial acreana foi, ao longo do tempo e espaço de territorialização das atividades econômicas (fronteira econômicas e suas frentes) que apontamos ser o principal componente de formação do território, sendo formada pelos atributos internos de cada indivíduo no momento da territorialização, mais os valores e símbolos construídos e adicionados no percurso temporal (FARIAS; SILVA, 2014). 
O ponto inicial de formação da identidade acreana ocorreu com a territorialização da produção de borracha a partir do látex nativo da seringueira. Com a decadência desta atividade por volta da década de 40 do século XX acarretada pelo cultivo racionalizado nos seringais de cultivo nas colônias inglesas na Ásia, muda-se a estrutura econômica regional com a inserção ou territorialização da agropecuária e como consequência também se muda os aspectos socioculturais. Então, as referências simbólicas dos territórios e territorialidades seringueira e fazendeira vivenciadas nos primeiros tempos da fronteira acreana, construíram a multitransterritorialidade ou transterritorialidade que constitui o território acreano (FARIAS; SILVA, 2014).

A multiterritorialidade implica, assim, a passagem de um território (ou territorialidade) para outro, assumindo-se novas condições em momentos diferentes de um mesmo processo TD-R. Se por acaso a multiterritorialidade se manifesta com a ênfase no estar-entre, no efetivamente híbrido, produzido através dessas distintas territorialidades, o melhor termo para designar este processo é a transterritorialidade (HAESBAERT; MONDARDO, 2010).

Sendo assim, para alcançar a compreensão necessária acerca da identidade e sua relação com o meio social no que concerne à Amazônia, é preciso inteirar-se de suas características e sua influência sobre este mesmo meio.

Euclides da Cunha (2000), nos ensaios sobre a Amazônia reunidos na obra Paraíso Perdido, sugere que, dada sua monstruosidade territorial, a região só poderia ser conhecida se dividida em partes. Em suas expedições, Cunha destacou não somente seu espanto diante da suntuosidade das matas, intransponíveis e verdes o ano inteiro, mas também outros aspectos, mais subjetivos, como o deslumbramento despertado nos aventureiros que as desbravavam, desafiavam-na em busca de extrair suas riquezas e eram frequentemente derrotados. Sobre suas características geográficas, a Amazônia se divide em três grupos, segundo Souza (2013), sendo o primeiro as florestas de igapós, cujos solos permanecem úmidos e alagadiços em áreas próximas aos rios e por um período aproximado de seis meses. Nestes espaços, as árvores podem alcançar 40 metros de altura e a vitória-régia, que plaina sobre as águas da região, podem atingir 4 metros de diâmetro. O segundo grupo de compõe das florestas de várzea, com árvores semelhantes às do igapó, de grande porte e altura similar, embora nestes espaços haja maior diversidade de espécies e as águas dos rios presentes sejam pretas. Por fim, o terceiro grupo é formado pelas florestas de terra firme, com árvores ainda mais portentosas, cuja altura varia entre 40 e 60 metros, com copas formando um dossel, que tornam seu entorno fechado, gerando escuridão e umidade em seu interior. Tais características podem ser observadas em terras mais 
altas e sua formação mistura-se a "outros tipos de associações locais, como os campos e os cerrados amazônicos" (SOUZA, 2013, p. 85).

Sobre tal geografia, relacionada a trechos específicos da região, Ab'Saber (2002) escreve que a Amazônia começa onde sobem e fecham as colinas onde antes podia-se observar extensos cerrados, ou ainda onde as matas secas desaparecem para dar lugar a intermináveis florestas de "terra firme".

Destarte, as descrições regionais da época, somadas ao fascínio pela novidade da descoberta dos potenciais econômicos da Amazônia, transmutaram-se, primeiramente em cobiça, dada a diversidade de suas riquezas, sobretudo após a descoberta do látex, de modo que a partir de 1870, atiçada pela avidez norte-americana ansiosa por suprir sua demanda pela borracha, teve início a corrida para a Amazônia com intensa migração de nordestinos, motivada, além da necessidade de força de trabalho, pelas secas que assolaram o nordeste em 1942 e, alguns anos depois, em 1877, período em que a região vai ganhando contornos específicos com a formação dos seringais e os primeiros núcleos habitacionais do Acre na parte mais ocidental da Amazônia brasileira (SOUZA, 2013). Posteriormente, tal fascínio passou a traduzir-se em produções literárias, momento em que, pode-se afirmar, a Amazônia passou a ter visibilidade, ao mesmo tempo em que começava a busca por uma identidade nacional, representada principalmente pelas descrições de Euclides da Cunha em seu Paraíso Perdido, como um resgate do ufanismo tão presente no primeiro período da geração romântica, que durou entre os anos de 1836 e 1852.

As definições do que era e do que significava a floresta surgiam em profusão, permeadas de adjetivos e expressões que se confundiam entre o real e a representação do real, como se, apesar da chegada dos imigrantes e desbravadores, sua verdadeira faceta permanecesse inacessível e resguardasse em seu âmago segredos incomunicáveis. Cumpre salientar que muitos destes homens não vieram para ficar, não vieram em busca de ser outros, pois "ser nordestino" já era sua identidade. Considerável parcela vinha em busca de sonhos e promessas de riquezas. Para tanto. atravessaram varadouros, transpuseram rios e enfrentaram perigos como doenças tropicais, ataques de índios e animais selvagens. A floresta era, para eles, o paradoxo do sertão. Para eles, portanto, a mudança de lugar representava um elemento muito mais simbólico, pois o espaço era:

entendido tanto como singular e como produto de uma dinâmica que é única, fruto de características históricas, econômicas, políticas, culturais e ambientais que são intrínsecas ao seu processo de formação, quanto como uma expressão da globalidade decorrente da hegemonização do capitalismo; e a simbólico, no 
qual a sociedade atribui valor e significado ao espaço, ou seja, o pertencimento (COUSIN, 2013, p. 8).

Destarte, o lugar também está relacionado a um espaço de construção de afetividades, moldadas por um conjunto de experiências vividas pelo sujeito em determinadas circunstâncias históricas, sociais e políticas, que de modo quase imperceptível acabam por influenciar em seu desenvolvimento enquanto pessoa, cidadão atuante do espaço em que se encontra e, portanto, capaz de modificá-lo e de ser, por ele, modificado.

Em uma revisão sobre o conceito de lugar os autores perceberam que há duas acepções principais, em dois eixos epistemológicos, o da Geografia Humanística, que considera lugar como produto da experiência humana e o da Geografia Radical na qual o lugar assume uma compreensão enquanto espaço de singularidade (STANISKI; KUNDLATSCH; PIREHOWSKI, 2014).

De fato, em uma perspectiva da Geografia Humanística, na qual o espaço e o lugar se relacionam, o lugar é mais concreto que o espaço e é considerado como a porção do espaço que é familiar, necessitando para isso experiência e valorização com significação para pessoa (TUAN, 1983, p.19).

De outro modo, o lugar é considerado resultado de características históricas e culturais pertinentes ao seu processo de formação, mas também pode estar relacionado como uma expressão de globalidade, para a perspectiva da Geografia Radical (LEITE, 1998).

Nesse sentido, compreende-se que o lugar é o seu espaço físico, dotado de identidade, forjada nas experiências dos indivíduos com o seu espaço singular, no qual as subjetividades humanas têm maior ênfase (STANISKI; KUNDLATSCH; PIREHOWSKI, 2014). Não obstante, a formação do lugar obedece ao percurso histórico dos fatos contraditórios da sociedade na qual está inserido.

Partindo desta premissa, quando se analisa a história do povoamento da Amazônia, seu passado de lutas, embates e perdas em nome do progresso, percebe-se a relevância de inserir a geografia e literatura do lugar ao currículo educacional profissionalizante daqueles que lidam com o presente e que atuam na transmissão desta história para as futuras gerações, visto que o ambiente é parte determinante na construção de novas identidades, uma ideia que, para Bauman (2012), nasceu da crise do pertencimento e do esforço que esta desencadeou no sentido de transpor a brecha entre 'deve' e o 'é' e erguer a realidade ao nível dos padrões estabelecidos, se consideradas as relações atávicas dos ex-seringueiros e indígenas do passado ao amazônida do século XXI. 
Pode-se mesmo afirmar que saindo de seu lugar de origem, o soldado da borracha, como era chamado o nordestino que passou a ocupar a Amazônia, desvinculou-se de seu ambiente original, o que, segundo Bauman (2012), provoca sensação de deslocamento, pois quando as identidades perdem as âncoras sociais, torna-se ainda mais importante para o indivíduo o encontro de uma 'identificação', visto que estes buscam um "nós" a que possam pedir acesso, e é este "nós" que passa a ser o cerne de um novo despertar de sentir-se pertencido. Além disso, se esses indivíduos que viveram a história perderam o seu sentimento de pertencimento com o lugar, como seus descendentes que nasceram foram do seringal poderiam ter esse aspecto? Diante disso, como resgatar o sentimento de pertencimento?

Assim, objetivamos propor um minicurso sobre a geografia do seringal tendo como principais materiais obras literárias regionalistas (em destaque a obra Terra Caída de José Potyguara) que possam contribuir para o resgate do sentimento de pertencimento ao mesmo tempo em que desperta a necessidade de descoberta do lugar, partindo da premissa de que o seringal, apesar de ser objeto de tantos estudos e pesquisas, ainda é espaço desconhecido e inexplorado, mesmo para aqueles que nele habitam e dele retiram seu sustento.

O procedimento adotado nessa pesquisa, quanto à abordagem foi a qualitativa. Quanto aos fins, foi realizada uma pesquisa qualitativa. Além disso, no que tange aos meios, adotou-se o estudo de caso, de modo que a metodologia se deu a partir de revisão bibliográfica ou revisão da literatura, a partir da qual buscou-se embasamento para o desenvolvimento da parte prática do projeto, discutindo o tema com base em referências teóricas publicadas em livros, revistas, periódicos e tantos outros suportes. Para tanto, foi usado como aporte de pesquisa o construtivismo de Jean Piaget, segundo o qual o ambiente social e o ambiente físico ocasionam oportunidades de interação entre sujeito e objeto, oportunizando ao aluno construir novos saberes e moldar a realidade que vivencia.

\section{MATERIAL E MÉTODOS}

As teorias de Jean Piaget revolucionaram a maneira de conceber o desenvolvimento humano e contribuíram na construção de novas teorias pedagógicas na medida em que o sujeito passa a ser visto como capaz de construir o conhecimento na interação com o meio físico e social, de maneira que este não é transmitido ao sujeito ou adquirido de fora para dentro, mas já está nele, de modo que a constituição do conhecimento, de acordo com a Epistemologia 
piagetiana, é ativa, o que significa dizer que o aluno é agente de seu próprio aprendizado (RIZZON, 2012).

Pensando nisso, houve a necessidade de estabelecer a definição de lugar do ponto de vista do estudante do Instituto Federal do Acre, lugar de referência ao qual ele considera-se pertencido. Partindo-se da premissa a forte influência do espaço imediato, bem como o sentimento de "pertencer-se", optou-se por considerar lugar, da perspectiva deste estudo, o município de Rio Branco, a segunda capital mais antiga da Amazônia Ocidental, ficando atrás apenas de Manaus. Rio Branco começou a ser povoado no final do século XIX, com a chegada dos nordestinos, e teve origem "na curva do rio" onde se localiza a Gameleira, árvore histórica que dá nome a um conhecido lugar na cidade onde os rio-branquenses se reúnem aos domingos para encontrar os amigos ou passar um tempo com a família à beira do Rio Acre. Historicamente, a Gameleira abrigava o porto por onde chegavam as primeiras embarcações trazendo os soldados da borracha, com seus valores, princípios e, principalmente, costumes, que marcam e fazem parte, até hoje, das características do povo do Acre, como a linguagem peculiar, por exemplo, permeada de expressões típicas do nordeste brasileiro.

Assim, elaborou-se o minicurso "Nosso lugar no seringal". A proposta surgiu como uma iniciativa para discutir a Amazônia, de forma mais restrita o seringal, como lugar de pertencimento do sujeito, como origem de sua história, seu passado, seu presente e sua construção identitária. Dessa forma, o lugar seria referência para seus habitantes, espaço de identificação com quem ele é ou se tornou, bem como com sua identidade cultural, também determinada pelo lugar em que se encontra inserido.

Tal proposta se fundamenta no tema Geografia e sua influência na construção da identidade cultural, tendo como base, especificamente, a geografia amazônica e tudo o que se escreveu sobre ela no romance Terra caída.

Nesse sentido, o Quadro 1 a seguir apresenta o planejamento geral do minicurso.

Quadro 1 -Planejamento geral do minicurso

\begin{tabular}{|l|l|}
\hline \multicolumn{2}{|c|}{ MINICURSO: Nosso "lugar" no seringal } \\
\hline OBJETIVO: & Geral: \\
Fomentar estudos sobre a influência da geografia amazônica sobre o sujeito que \\
habita a região utilizando uma perspectiva interdisciplinar \\
Específicos: \\
- Desenvolver o sentimento de pertencimento deste sujeito em contato com o lugar \\
em que se encontra inserido. \\
- Apresentar conceitos dialógicos interdisciplinares de geografia e literatura, \\
ressaltando uma abordagem significativa para a formação acadêmica do \\
participante.
\end{tabular}




\begin{tabular}{|l|l|}
\hline EXECUÇÃO & 08 horas \\
\hline RECURSOS & $\begin{array}{l}\text { - Apresentação da obra Terra caída em aula expositiva/participativa, ressaltando } \\
\text { as características geográficas presentes no livro; } \\
\text { - Comparar com o que é percebido do clima, do solo e de outros aspectos } \\
\text { observáveis da região amazônica; } \\
\text { - Partir do lugar em que se vive; } \\
\text {-Resgatar todo o cenário de como vivia o seringueiro. }\end{array}$ \\
\hline - Computador e Datashow; \\
- Cópia de material didático para realização da atividade prática
\end{tabular}

Diante do planejamento geral, as etapas de execução poderão ser realizadas da seguinte forma:

A linguagem é parte indissociável da identidade de um povo. Partindo desta premissa, os alunos são estimulados, primeiramente, a reconhecer-se a partir da fala, sotaque e variação linguística próprios da região em que moram, tendo como referência, espaços diferentes, em que os falares são outros, com características também próprias da região.

Tal atividade de análise é parte da etapa prática da pesquisa, que tem duração de 120 minutos. O objetivo durante este processo é conhecer a literatura amazônica e sua importância para o reconhecimento da identidade e do sentimento de pertencimento. Para tanto, pode ser feita uma apresentação de slides com algumas literaturas e alguns resumos a respeito das obras e um diálogo com os alunos para saber quais tem o conhecimento sobre o assunto e quais não ouviram falar, destacando ainda peculiaridades da fala inerentes à região discutida nesse trabalho.

Na segunda etapa, também com 120 minutos apresenta-se alguns trechos para que os alunos percebam que nas literaturas há várias descrições do clima, solo e outras características físicas de Rio Branco, e partindo dos trechos podemos desenvolver vários conteúdos escolares, vejamos:

Lá pela meia noite, o tempo começou a mudar. Encobrindo as estrelas, grandes massas de nuvens escurar invadiram o céu. Não tardou que um ventinho começasse a soprar, sacudindo as copas das árvores, enfunando os mosqueteiros das redes. 
- Eta!,qui a cruviana vem aí! - exclama um seringueiro de vigia no terreiro da hospedagem.

Sempre alerta, Teodoro bota a cara barbada fora do mosqueteiro, olha o céu e confirma:

- Hum!... É friagem e da braba! (POTYGUARA, 1998, p. 226).

O terceiro momento utilizará somente 60 minutos, o professor instigará os alunos sobre suas origens indagando se os mesmos conhecem a trajetória de seus pais e avós, de onde vieram, quais as histórias eles contam e assim partindo do lugar onde eles vivem hoje tentar imaginar o que era a vida no seringal, quais as diferenças e semelhanças com os dias atuais.

$\mathrm{Na}$ quarta etapa, os alunos serão apresentados ao cenário do seringal e como vivia o seringueiro:

\footnotetext{
Num campo apertado entre a mata e o rio, a sede do seringal é apena um embrião de povoado, um arremedo de rua paralela ao barranco. Perto do porto, o primeiro casarão de madeira, coberto de zinco, é o armazém. Ao lado, ligado por um trapiche de paxiúba, o escritório ostenta na fachada duas grandes letras vermelhas e já um tanto desbotadas: A. M. - iniciais do coronel Antônio Monteiro. Em seguida, estão a casa do Tiburtino, a do guarda-livros, a escola, o curral e, por último, a residência do proprietário, um bonito chalé de madeira de lei, cercado de varandas (POTYGUARA, 1998, p. 226).
}

Além dos trechos que descrevem o panorama da vida no seringal também pode-se mostrar imagens (impressas ou apresentadas em projeção de slides) como a figura 1, que mostra como era a vida no seringal, e a figura 2, que mostra a produção de borracha disposta para ser embarcada para a venda.

Figura 1 - A alma acreana: a Era dos seringais. ${ }^{1}$

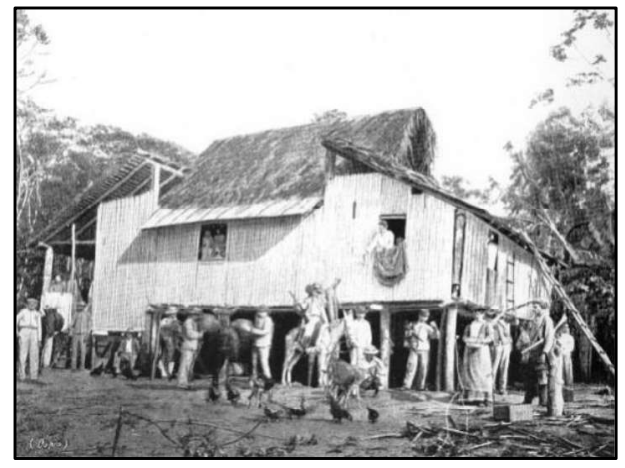

Fonte: Blog Alma acreana

\footnotetext{
${ }^{1}$ Disponível em https://almaacreana.blogspot.com/2012/02/era-dos-seringais.html Acesso em 30 jun. 2019
} 
Figura 2 - Quiel: Casas do Acre ${ }^{2}$

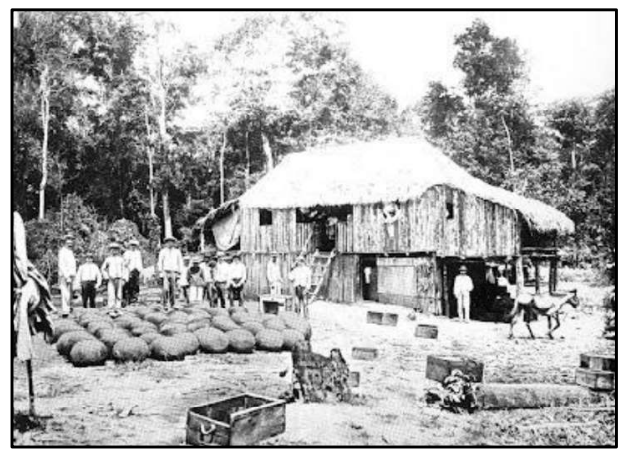

Fonte: Blog Alma acreana

No final da oficina, objetivando qualificar o aprendizado dos alunos, pode-se solicitar uma redação como método avaliativo com o objetivo de avaliar os aspectos seguintes:

- Levantamento dos conhecimentos prévios do aluno em relação aos conteúdos propostos a partir de situações que permitam identificar se o aluno:

1. compreende textos orais,

2. utiliza a fala espontânea e a fala planejada em ocasiões que exigem desenvoltura comunicativa e,

3. posiciona-se diante da fala do outro.

Destarte, a produção deverá obedecer aos seguintes critérios:

- Texto argumentativo que demonstre domínio razoável das regras e convenções de escrita;

- Posicionamento crítico diante do assunto abordado através de recursos de progressão textual e discursiva, como paráfrases dos textos lidos ou da fala do professor em aula expositiva;

- Domínio razoável dos conceitos que caracterizam o ambiente amazônico, bem como o lugar a que o indivíduo pertence, partindo da perspectiva micro para macro (ou local para global);

- Emprego de dados dos textos utilizados durante a oficina para a construção de mecanismos argumentativos.

O escopo deste trabalho, diante das atividades desenvolvidas e das discussões fomentadas entre os alunos, pode considerar-se satisfatoriamente alcançado. Inicialmente, partiu-se da exploração e hipóteses dos conhecimentos prévios dos alunos, buscando identificar "brechas" onde seria possível agregar novos saberes e desenvolver aprendizagens significativas

\footnotetext{
${ }^{2}$ Disponível em https://almaacreana.blogspot.com/2012/02/era-dos-seringais.html Acesso em: 30 jun. 2019
} 
a partir do conhecimento que eles já haviam construído ao longo de suas vivências, dentro e fora do ambiente escolar.

Conforme as discussões acontecem e novos conflitos acerca do tema podem naturalmente aparecer, os alunos tornam-se cada vez mais participativos, contribuindo com falas que, por vezes, divergiam da fala de outro, o que é considerado positivo, pois fomenta o desenvolvimento do pensamento crítico diante dos problemas apresentados e faz com que o estudante assuma o protagonismo do que está aprendendo, cumprindo as prerrogativas do que se propôs na fase de planejamento no que tange ao construtivismo piagetiano.

De modo natural e sem imposições de nenhuma natureza, o aluno será capaz de perceber as influências do lugar em que vive na formação de sua identidade, ao mesmo tempo em que se apropria, autonomamente, de conceitos relacionados à geografia amazônica, suas características sociais, econômicas, financeiras e toda a questão subjetiva que envolve tais aspectos, como o orgulho inerente à história de independência do Estado do Acre, personificada nas lutas para libertar-se do território boliviano e fazer parte do Brasil.

Assim, será possível construir uma linha do tempo fundamentada nas produções orais dos estudantes, por ocasião do desenvolvimento das atividades práticas, o que torna a aprendizagem ainda mais significativa. A partir da ideia de pertencimento, de agente do espaço em que vive, o indivíduo pode finalmente alcançar a compreensão da importância de seu espaço no mundo e não apenas agregar mais saberes à gama de conhecimentos que já possui, mas, ainda mais importante, reconhecer seu lugar no mundo e seu papel diante do que ocorre em sua comunidade, partindo de uma perspectiva local, para uma atuação, posteriormente global, o que o torna responsável pela preservação do ambiente enquanto seu lugar de morada e, portanto, parte de sua construção identitária.

Por fim, apropriados do conteúdo e dos critérios avaliativos, é possível escrever produtivamente a redação proposta pelo método avaliativo, em que se valoriza, sobretudo, o conteúdo acerca da geografia amazônica, mas desenvolve-se, também, habilidades importantes de escrita, como as sugeridas na metodologia deste trabalho.

\section{RESULTADOS E DISCUSSÃO}

O processo educacional não se configura como um conceito pronto e acabado, mas tal como a linguagem se modifica, se aperfeiçoa e evolui constantemente. Por esta razão, as disciplinas escolares encontram-se cada vez mais integradas e perderam o caráter individual 
que reduzia os processos de aprendizagem a conteúdos compartimentados, sem relação entre si. Desse modo, a leitura deve ser explorada em todas as disciplinas, tal como a matemática pode ser trabalhada em geografia, através da análise de mapas e gráficos, a geografia pode ser trabalhada em história, a partir da mudança e transformação de espaços que impactam na organização de uma sociedade, e assim por diante. Todos os saberes são significativos, mas nem sempre foram acessíveis a todos. Quando se passou a encará-los como elementos fundamentais e integrantes da identidade do sujeito, percebeu-se a importância de desconstruir antigos dogmas e práticas excludentes, que deixavam alguns atores à margem do processo de ensino.

Portanto, nos propusemos a desenvolver os saberes acerca do lugar onde se nasceu e viveu, bem como sua influência, coletiva e individual, sobre os costumes do próprio povo, considerando que não é mais possível conceber um ensino dissociado do que é significante para os protagonistas do processo educacional.

Por fim, esta pesquisa deve possibilitar ao participante a competência de identificar-se com o lugar em questão, sua importância para a história do país e as disputas que ainda instiga no âmbito da política nacional e internacional, conceituando e reconhecendo lugares do qual faz parte, bem como valorizando a cultura oriunda do ambiente amazônico, a partir da qual se desenvolverá a consciência necessária para perceber sua importância.

\section{CONCLUSÃO}

Sendo o lugar parte indissociável da identidade da pessoa humana, construída a partir da linguagem, é inegável a necessidade de desenvolver e estimular métodos que melhor auxiliem o homem quanto à compreensão do pertencimento geográfico e seus impactos na vida de cada indivíduo, visto que seus temores, crenças e tudo que o sustenta no espaço a que pertence está arraigado nos simbolismos do lugar onde nasceu, cresceu e viveu (ou ainda vive).

No que tange ao lugar amazônico, objeto de análise deste trabalho, o peso de sua importância é ainda maior, uma vez que é da floresta que o sujeito retira, ainda, insumos que garantem sua subsistência, é a floresta que representa, nesta região, alento econômico para muitas famílias que vivem do que ela oferece, de modo que o homem amazônico acaba, fatalmente, confundindo-se com o lugar, sobretudo quando não conhece outro modo de viver que não este, herdado de seus ancestrais índios e/ou nordestinos. 
Em todas estas questões reside a relevância de fomentar novos olhares para tais questões, não com o intuito de convidar o povo amazônico a uma nova vida, pois para ele já é o bastante ser quem é, mas para que encontre também significado em sua existência ao mesmo tempo que perceba a importância de preservar seu meio, garantia de vida também para gerações vindouras.

\section{REFERÊNCIAS}

AB'SABER, Aziz N. Bases para o estudo dos ecossistemas da Amazônia brasileira. Revista estudos avançados 16 (45), 2002. Disponível em: https://www.researchgate.net/publication/240971918 Bases para o estudo dos ecossistema s_da_Amazonia_brasileira/link/567b084708aele63f1df83e8/download. Acesso em: 31 mai. 2019.

ACRE. Secretaria de Estado de Meio Ambiente. Cultural político: memórias, identidades e territorialidade. ZEE/AC, fase II, escala 1:250.000 / Programa Estadual de Zoneamento Ecológico-Econômico do Acre. - Rio Branco: SEMA Acre, 2010.

A SELVA. Direção: Márcio Souza. Produção: L.M. Produções Cinematográficas Ltda. Intérpretes: Rui Gomes, (Alberto) Ana Maria SIlva (D. Iaiá), Farias de Carvalho (Juca Tristão), Moacir Bezerra (Agostinho), Leon Manichander (Firmino), Pedro Amorim (Guerreiro), Expedito Teodoro (Balbino), Guanabara de Araujo (J. B. Aragão), Maranhão (Tiago), Jamaci Bentes (Macedo). Roteiro: Márcio Souza. Rio de Janeiro. Videocassete, (80min) eastman color, $35 \mathrm{~mm}$.

BAUMAN, Z. Identidade: entrevista a Benedetto Vecchii/ZygmuntBauman. Rio de Janeiro: Zahar. 2005.

BOSI, Alfredo. História concisa da literatura brasileira. 40 ed. São Paulo: Cultrix, 2003.

COUSIN, C. S. Pertencimento ao lugar e a formação de educadores ambientais: um diálogo necessário. In: EPEA - Encontro Pesquisa em Educação Ambiental, 7, 2013, Rio Claro - SP. Anais... 2013. Disponível em: http://www.epea.tmp.br/epea2013 anais/pdfs/plenary/01301.pdf. Acesso em: 06 de dez. 2019.

CUNHA, Euclides da. Um paraíso perdido: reunião de ensaios amazônicos. Seleção e coordenação de Hildon Rocha. Brasília: Senado Federal, Conselho Editorial, 2000. (Coleção Brasil 500 anos)

Preâmbulo. In: RANGEL, Alberto. Inferno verde $5^{\text {a }}$ ed. Manaus: Valer / Governo do Estado do Amazonas, 2001

FARIAS, Cleilton Sampaio; SILVA, Silvio Simione da. As fronteiras da fronteira e a expressão da multitransterritorialidade acreana. Entre-Lugar, Dourados, MS, ano 5, n.7, 1. semestre de 2014. 
GOUVEIA, Fernanda Paixão. A expansão dos Institutos Federais de Educação, Ciência e Tecnologia no território brasileiro: entre o local e o nacional. Espaço e Economia - Revista brasileira de geografia econômica, 2016 Ano V, Número 9

HAESBAERT, Rogério. Des-territorialização e Identidade: a rede "gaúcha" no Nordeste. Niterói: EdUFF,1997.

HALL, Stuart. A identidade cultural na pós-modernidade. Tradução Tomaz Tadeu da Silva, Guaracira Lopes Louro-11. ed. -Rio de Janeiro: DP\&A, 2006.

LEITE, A. F. O Lugar: Duas Acepções Geográficas. Anuário do Instituto de Geociências UFRJ, 21, p. 9-20,1998.

MONDARDO, Marcos. Transterritorialidade e antropofagia: territorialidades de trânsito numa perspectiva brasileiro-latino-americana. GEOgraphia. Vol. 12, No. 24 (2010).

PAIVA, Marco Aurélio Coelho de. O sertão amazônico: o inferno de Alberto Rangel Sociologias, Porto Alegre, ano 13, no 26, jan./abr. 2011, p. 332-362 334

RANGEL, Alberto. Inferno Verde. $5^{\text {a }}$ ed. Manaus: Valer / Governo do Estado do Amazonas, 2001

POTYGUARA, José. Terra Caída. Ed. Fundação Cultural. 1998.

RIZZON, Gisele. A sala de aula sob o olhar do construtivismo piagetiano: perspectivas e implicações. Maio 2010, Caxias do Sul, RS. ISSN 2177 644x

STANISKI, Adelita; KUNDLATSCH, Cesar Augusto; PIREHOWSKI, Dariane. O conceito de lugar e suas diferentes abordagens. Perspectiva geográfica. UNIOESTE V.9, N.11 2014.

SOUZA, Edevaldo Aparecido; PEDON, Nelson Rodrigo. Território e identidade. Revista Eletrônica da Associação dos Geógrafos Brasileiros - Seção Três Lagoas Três Lagoas - MS, V 1 - n. ${ }^{\circ} 6$ - ano 4, Novembro de 2007.

SOUZA, Carlos Alberto Alves de. História do Acre: novos temas, nova abordagem. $9^{\circ}$ edição. Ed. ADUFAC. Rio Branco, 2013.

TUAN, Y. -F. Espaço e Lugar: a perspectiva da experiência. São Paulo: DIFEL, 1983. 